\title{
EMOTIONAL INTENSITY: MEASUREMENT AND THEORETICAL IMPLICATIONS
}

\author{
JO-ANNE BACHOROWSKI* and ELLEN B. BRAATEN \\ Department of Psychology, University of Colorado at Denver, P.O. Box 173364, Denver, \\ CO 80217-3364, U.S.A.
}

(Received 23 October 1993)

\begin{abstract}
Summary - The individual difference construct of emotional intensity has received substantial theoretical and empirical attention. However, the principal measure used to measure emotional intensity appears to confound frequency with intensity in the response format. We developed the Emotional Intensity Scale (EIS) to make available a measure of emotional intensity independent of frequency. The EIS demonstrated strong internal reliability and temporal stability. Some of the theoretical implications of the correlations that were obtained among positive affect, negative affect, Extraversion, and Neuroticism are described.
\end{abstract}

\section{INTRODUCTION}

Considerable empirical and theoretical attention has recently been given to the interplay between emotional states and personality traits as well as to the relations between emotional states and behavior. One of the dominant themes in much of this work has been the hypothesized individual difference dimension of affect or emotional intensity (Larsen \& Diener, 1985, 1987) and its relations to such variables as cognitive differentiation and personal striving (Emmons \& King, 1989), vicarious responding (Eisenberg, Fabes, Schaller, Miller, Carlo, Poulin, Shea \& Shell, 1991), and facial musculature responses (Jancke, 1993).

Differences in levels of affect intensity have been assumed to reflect differences in the intensity of emotional experience, regardless of the hedonic valence of those states. Larsen and Diener's (1985, 1987; Diener, Larsen, Levine \& Emmons, 1985) elaborations of the construct have included the notion that individuals who experience intense positive emotions also tend to experience intense negative emotions. In this sense, individuals are thought to differ along an intensity dimension but not along an emotional valence dimension.

Cooper and McConville (1993) took exception to these views. These authors contended that the affect intensity construct is a statistical artifact of the affect intensity score calculation procedures. In their view, positive and negative affect intensity values are equivalent to mean levels of positive and negative affect. They suggested that emotional intensity should be viewed as a blend of trait extraversion and trait neuroticism [rather than as a construct with independent psychological relevance (Cooper \& McConville, 1989, 1993)].

At this stage in the delineation of the emotional intensity construct, it seems reasonable to separate theoretical from measurement concerns. We contend that the emotional intensity construct has considerable theoretical utility, particularly in contributing to a more complete characterization of the relationships among the personality traits of extraversion and neuroticism, their psychobiological underpinnings, and behavior.

One framework for understanding impulsive and anxious behaviors is a synthesis of Eysenck's $(1967,1981)$ model of personality incorporating the three arousal systems described by Gray (1981; see also Fowles, 1980, 1987). Wallace, Bachorowski and Newman (1991; Bachorowski \& Newman, 1990) proposed that Gray's theoretical Behavioral Inhibition, Behavioral Activation, and Nonspecific Arousal Systems can be linked to Eysenck's orthogonal personality dimensions of Extraversion and Neuroticism. In this synthesis, the Extraversion dimension was proposed to be a stimulus sensitivity and characteristic response tendency dimension whose neurophysiological underpinnings were the relative strengths of Behavioral Inhibition and Behavioral Activation system functions. The force and speed of behavior and associated cognitive changes that occurred subsequent to Behavioral Inhibition

*To whom all correspondence should be addressed. 
and Behavioral Activation System activity were hypothesized to be the result of the level of Nonspecific Arousal System reactivity, which in turn was said to be indexed by an individual's level of Neuroticism.

Although Wallace et al.'s (1991) framework could be applied to impulsive behavior, anxious behavior, and the phenomenon of 'anxious impulsivity', no consideration was given to the emotional concomitants of these behavioral response styles. To accommodate this gap, we hypothesize that extraverts are particularly prone to experiencing positive emotional states such as pleasure and elation because of their sensitivity to stimuli such as cues for reward. Conversely, introverts, by virtue of their sensitivity to cues such as punishment and uncertainty, are apt to experience negative emotional states such as sadness and frustration. The typical intensity with which emotions are experienced is associated with an individual's location on the Neuroticism dimension. Thus, the trait dimension of Extraversion is hypothesized to reflect the typical valence of felt emotional experiences as well as characteristic stimulus sensitivities and response tendencies. Correspondingly, Neuroticism is thought to reflect emotional intensity in addition to behavioral intensity and associated cognitive functions. Reworking Gray's arousal system framework somewhat, positive emotional states are associated with Behavioral Activation System functions, negative emotional states with Behavioral Inhibition System functions, and the intensity of emotional states (regardless of valence) with Nonspecific Arousal System functions.

This formulation certainly has areas of overlap with the presentations of others (notably Derryberry \& Rothbart, 1988; Eysenck \& M. Eysenck, 1985; Frijda, 1988; Gray, 1981, 1987; Larsen \& Ketelaar, 1991; Russell, 1980, 1991; Strelau, 1987; Watson \& Tellegen, 1985). At this juncture, it is not our intent to sort through the specific similarities and differences among these authors but to underscore the importance of considering both valence and intensity in work that examines emotional responding and its relations with behavior.

Despite the considerable theoretical attention given to emotional intensity, measurement problems remain. The Affect Intensity Measure [AIM (Larsen \& Diener, 1987)] is a well-validated self-report inventory used to index trait levels of affect intensity. However, inspection of the response format indicates that the AIM does not provide a pure estimate of affect intensity. Instead, the scale appears to measure some combination of the frequency and intensity with which people experience a variety of emotions (see also Cooper \& McConville, 1993). Differences in intensity are embedded within each of the 40 items. For example, a low intensity item is "My negative moods are mild in intensity," whereas a high intensity item is "When I feel happy it is a strong type of exuberance." Unfortunately, differences in frequency appear to be encoded in the response format. Respondents are asked to use a six point scale ranging from 'Never' to 'Always' to indicate how frequently that level of emotional intensity is experienced. Thus, each item assesses both frequency and intensity.

We developed the Emotional Intensity Scale (EIS) to have a measure of the intensity of positive and negative emotional states unconfounded by the frequency with which those states are experienced.

\section{METHOD}

\section{Subjects and procedure}

The norming sample included 104 undergraduate students (40 males and 64 females) who participated in exchange for extra credit in their Introductory Psychology course (mean age $=20.58$ yr, SD = 4.11). Ss completed the EIS, AIM (Larsen \& Diener, 1987), and Eysenck Personality Questionnaire [EPQ (Eysenck \& S. Eysenck, 1975)] in a classroom setting. Nine weeks later, 58 of these $S$ s completed the EIS a second time.

A separate sample of $58 \mathrm{Ss}$ (18 males and 40 females) came from an upper division psychology class (mean age $=25.88 \mathrm{yr}, \mathrm{SD}=7.13$ ). These $S \mathrm{~s}$, who also received extra credit toward their course grade in exchange for participation, completed the EIS weekly for a period of 13 weeks (each $S$ completed the EIS at least nine times over the 13 week interval).

\section{EIS Description}

The EIS (shown in the Appendix) is a self-report measure in which $S$ s endorse one of five choices for each of 30 items. For each item, the response format was intended to assess the usual, or typical, 
Table I. Descriptive statistics for the total, positive, and negative scales scores within the total, male, and female samples

\begin{tabular}{|c|c|c|c|c|c|c|c|c|c|}
\hline & \multicolumn{3}{|c|}{ Total sample $(n=104)$} & \multicolumn{3}{|c|}{ Males $(n-40)$} & \multicolumn{3}{|c|}{ Fenlales $(n=64)$} \\
\hline & EIS & EIS-POS & EIS-NEG & EIS & EIS-POS & EIS-NEG & EIS & EIS-POS & EIS-NEG \\
\hline Mean & 105.66 & 51.68 & 53.98 & 98.25 & 50.00 & 48.25 & 110.30 & 52.73 & 57.56 \\
\hline Median & 107.50 & 52.00 & 54.00 & 100.50 & 51.00 & 49.50 & 111.00 & 53.00 & 57.00 \\
\hline Range & $64-133$ & $33-64$ & $27-73$ & $64-124$ & $33-62$ & $27-62$ & $78-133$ & $35-64$ & 31.00 \\
\hline SD & 13.81 & 6.56 & 9.20 & 12.93 & 6.93 & 8.56 & 12.32 & 6.13 & 7.69 \\
\hline
\end{tabular}

Note: EIS, Emotional Intensity Scale, total score; EIS-POS, EIS positive emotion item score; EIS-NEG, EIS negative emotion item score.

intensity of the described emotion when that emotion is experienced. The items were not intended to measure the frequency with which the assessed emotions are experienced. Items were written to sample emotional experiences that are familiar to most people. In preliminary versions of the EIS (Braaten \& Bachorowski, 1993), items werc dropped if they were weakly correlated with the total score $(r<.30)$. In this version of the EIS, 14 items measure positive emotions such as joy and liveliness, while the remaining 16 items assess an array of negative emotions, including anger and frustration. Overall, 12 items ask about emotional responses to relatively detailed scenarios whereas the remaining 18 items specify an emotion without providing substantive contextual information. The EIS is scored by summing the individual item scores (1-5) after correcting for reverse keying in nine items. The total EIS score can range from a minimum of 30 to a maximum of 150 . The same system is used to obtain subtest scores for positive and negative emotions.

\section{RESULTS}

Analyses were conducted using both the total EIS score (EIS) score as well as the subtotal scores for positive (EIS-POS) and negative (EIS-NEG) emotion items. Since female $S$ s reported experiencing greater degrees of emotional intensity than did male $S \mathrm{~s}[t(1,102)=-4.76, P<0.001]$, separate analyses were conducted for the total sample and both genders. The results of descriptive analyses for the EIS, EIS-POS and EIS-NEG scores are provided in Table 1.

Coefficient alphas were computed to assess the internal reliability of the EIS. The magnitude of these alphas indicate that the EIS has a high degree of internal consistency: Coefficient $\alpha$ was 0.90 for the total sample, 0.88 for the male sample, and 0.89 for the female sample. The item-total correlations for the total $S$ sample ranged from a low of 0.37 to a high of 0.65 and were all statistically significant at the $P<0.001$ level. As expected because of the smaller sample sizes, the range of the item-total correlations was greater using the male and female samples than it was for the total sample. These correlations ranged from 0.19 to 0.75 for the males and from 0.32 to 0.68 for the females.

Test-retest correlations were used as an additional index of reliability. These correlations, shown in Table 2, indicate that scores were stable for the EIS as well as for the EIS-POS and EIS-NEG scores across the total, male, and female samples. Score stability was especially apparent for the EIS and EIS-NEG scores from the male Ss. The correlations were somewhat weaker for the EIS-POS scores. However, all nine test-retest correlations were statistically significant at the $P<0.001$ level.

Outcomes for the sample of $S$ s who completed the EIS weekly for a period of 13 weeks provided additional evidence for the stability of EIS scores over time. The correlations obtained between the first and any of the subsequent administrations ranged from 0.57 to 0.84 . With a minimum of 37 and

Table 2. Test-retest reliability coefficients

\begin{tabular}{lccc}
\hline & $\begin{array}{c}\text { Total sample } \\
(n=58)\end{array}$ & $\begin{array}{c}\text { Males } \\
(n=18)\end{array}$ & $\begin{array}{c}\text { Females } \\
(n=40)\end{array}$ \\
\hline EIS No. 1 with EIS No. 2 & 0.83 & 0.91 & 0.75 \\
EIS-POS No. 1 with EIS-POS No. 2 & 0.71 & 0.75 & 0.71 \\
EIS-NEG No. 1 with EIS-NEG No. 2 & 0.87 & 0.92 & 0.78 \\
\hline Note: EIS, Emotional Intensity Scale, total score; EIS-POS, EIS positive emotion item \\
score; EIS-NEG, EIS negative emotion item score. The tes-retest interval was 9 \\
weeks. All cotrelations were statistically significant at the 0.001 level.
\end{tabular}


Table 3. Intercorrelations between EIS and AIM, EPQ-E, and EPQ-N

\begin{tabular}{|c|c|c|c|c|c|c|}
\hline & EIS & EIS-POS & EIS-NEG & AIM & EPQ-E & EPQ-N \\
\hline \multicolumn{7}{|c|}{ Total Sample $(n=104)$} \\
\hline EIS & 1.00 & & & & & \\
\hline EIS-POS & $0.82 *$ & 1.00 & & & & \\
\hline EIS-NEG & $0.91^{*}$ & $0.52 *$ & 1.00 & & & \\
\hline AIM & $0.48^{*}$ & $0.37 *$ & $0.45^{*}$ & 1.00 & & \\
\hline EPQ-E & 0.23 & $0.41 *$ & 0.06 & $0.27 *$ & 1.00 & \\
\hline EPQ-N & $0.54^{*}$ & 0.23 & $0.64^{*}$ & $0.34^{*}$ & 0.03 & 1.00 \\
\hline \multicolumn{7}{|c|}{ Male Sample $(n=40)$} \\
\hline EIS & 1.00 & & & & & \\
\hline EIS-POS & $0.79 *$ & 1.00 & & & & \\
\hline EIS-NEG & $0.87 *$ & 0.39 & 1.00 & & & \\
\hline AIM & 0.38 & 0.34 & 0.30 & 1.00 & & \\
\hline EPQ-E & 0.28 & $0.49 *$ & 0.03 & 0.05 & 1.00 & \\
\hline EPQ-N & $0.42 *$ & 0.02 & $0.62^{*}$ & 0.07 & -0.01 & 1.00 \\
\hline \multicolumn{7}{|c|}{ Female Sample $(n=64)$} \\
\hline EIS & 1.00 & & & & & \\
\hline EIS-POS & $0.86^{*}$ & 1.00 & & & & \\
\hline EIS-NEG & $0.91^{*}$ & $0.58^{*}$ & 1.00 & & & \\
\hline AIM & $0.45^{*}$ & $0.33^{*}$ & $0.45^{*}$ & 1.00 & & \\
\hline EPQ-E & 0.22 & $0.36^{*}$ & 0.06 & $0.43 *$ & 1.00 & \\
\hline EPQ-N & $0.49 *$ & 0.28 & $0.57^{*}$ & $0.41^{*}$ & 0.04 & 1.00 \\
\hline
\end{tabular}

Note: EIS, Emotional Intensity Scale, total score; EIS-POS, EIS positive emotion score; EIS-NEG, EIS negative emotion score; AIM, Affect Intensity Measure; EPQ-E, Eysenck Personality Questionnaire, Extraversion scale; EPQ-N, Eysenck Personality Questionnaire, Neuroticism scale; correlations marked with an asterisk were significant at the 0.01 level or beyond.

a maximum of 58 cases per correlation, these 12 correlations were all statistically significant $(P<0.001)$.

Table 3 shows the correlations among the EIS, AIM, EPQ Extraversion (EPQ-E), and EPQ Neuroticism (EPQ-N) scores. Although the EIS correlated significantly with the AIM, $r=0.48$, the amount of variance left unexplained by the correlation $(77 \%)$ indicates that the two measures are tapping similar but nonredundant aspects of emotional functioning. Similarly, the correlations between the EIS and both EPQ scales indicate that these measures are related in complementary ways. The pattern of correlations among the EIS-POS, EIS-NEG, EPQ-E, and EPQ-N scores is of particular interest. EIS-POS scores were more strongly associated with EPQ-E than EPQ-N scores, whereas EIS-NEG scores were very strongly associated with EPQ-N but not EPQ-E scores. This pattern indicates that intense positive emotional states are associated with Extraversion but that more intense negative emotional states are associated with Neuroticism.

Similar patterns of correlations were obtained within the male and female samples. In both samples, strong but nonredundant relations between the EIS and AIM were obtained. The aforementioned pattern of correlations among the EIS-POS, EIS-NEG, EPQ-E, and EPQ-N scores was also observed separately in both samples. The divergence between intense positive and negative emotional experiences and Extraversion and Neuroticism was very strong for the male sample. For the female $\mathrm{Ss}$, intense positive emotional states were also associated with Neuroticism (although to a lesser extent than were negative emotional states).

\section{DISCUSSION}

The rationale underlying the development of the EIS was to have available a measure of emotional intensity that assesses the intensity of emotions, independent of the frequency with which those emotions are experienced. This approach differs from the AIM, which more obviously assesses both the intensity and frequency with which emotions are experienced. The significant, moderate correlations that were obtained between EIS and AIM scores indicate that the two scales tap related yet distinct aspects of emotional functioning. Some of the variance left unexplained by these associations is assumed to result from the difference in the measurement of intensity between the two measures. 
The results indicate that the EIS is a highly reliable instrument. This outcome was the case for measures of internal consistency as well as stability over time (using two independent $S$ samples). As is often the case with measures of emotional function (Fujita, Diener \& Sandvik, 1991; Larsen \& Diener, 1987), female $S$ s scored significantly higher on the EIS than did male Ss. However, the results of descriptive statistics and the various correlations with other measures indicated that the scale operates in a similar manner for male and female $S$ s.

Correlations among the EIS, and EPQ-Extraversion and EPQ-Neuroticism scales are relevant to theories that integrate personality with emotional experience. We had hypothesized a specific pattern of intercorrelations derived from an extension of one integration of Eysenck's (1967) and Gray's $(1981,1987)$ theories of personality (Bachorowski \& Newman, 1990; Wallace et al., 1991). These predictions were only partially confirmed. Positive correlations between the total EIS and EPQ-N scores indicated that the more highly neurotic $S$ s reported experiencing more intense emotional states. Thus, there was support for the notion that $S$ s with more reactive or labile Nonspecific Arousal System activity also experience intense emotional states, be they positive or negative. The individual correlations among the EIS-POS, EIS-NEG, EPQ-E, and EPQ-N scores did not provide compelling evidence for the hypothesis that persons with dominant Behavioral Inhibition Systems are more likely to experience negative affect whereas Behavioral Activation System-dominant persons are more likely to experience positive affect. Although EIS-POS scores were positively correlated with Extraversion scores, these correlations were not particularly strong. In addition, EIS-NEG scores were more clearly aligned with Neuroticism (and not negatively correlated with Extraversion, as was anticipated). These correlations were consistent with Larsen and Ketclaar's (1991) use of Eysenck's and Gray's theories.

It is clearly necessary to move beyond an examination of the intercorrelations among various self-report measures so that a more meaningful account of emotional experience can develop. One goal is to understand the behavioral and emotional responses elicited by specific contextual variables, such as reward and punishment, and the psychobiological underpinnings of these responses. The results of validation studies will provide a more cohesive account of the relations among emotional intensity, personality, and both adaptive and maladaptive behavior.

Acknowledgements-This research was supported by a University of Colorado at Denver Junior Faculty Development Award to Jo-Anne Bachorowski. We appreciate the suggestions made by Michael J. Owren on an earlier version of this manuscript. Persons may obtain a copy of the Emotional Intensity Scale by contacting Jo-Anne Bachorowski.

\section{REFERENCES}

Bachorowski, J. A. \& Newman, J. P. (1990). Impulsive motor behavior: The effects of personality and goal salience. Journal of Personality and Social Psychology, 58, 512-518.

Braaten, E. B. \& Bachorowski, J. A. (1993, April). Emotional intensity scale: Psychometric and behavioral validation. Paper presented at the Annual Meeting, Rocky Mountain Psychological Association, Phoenix, Ariz.

Cooper, C. \& McConville, C. (1989). The factorial equivalence of state Anxiety-negative affect and state Extraversion-positive affect. Personality and Individual Differences, 10, 919-920.

Cooper, C. \& McConville, C. (1993). Affect intensity: Factor or artifact? Personality and Individual Differences, 14, $135-143$.

Derryberry, D. \& Rothbart, M. K. (1988). Arousal, affect, and attention as components of temperament. Journal of Personality and Social Psychology, 55, 958-966.

Diener, E., Larsen, R. J., Levine, S. \& Emmons, R. A. (1985). Intensity and frequency: Dimensions underlying positive and negative affect. Journal of Personality and Social Psychology, 48, 1253-1265.

Eisenberg, N., Fabes, R. A., Schaller, M., Miller, P., Carlo, G., Poulin, R., Shea, C. \& Shell, R. (1991). Personality and socialization correlates of vicarious emotional responding. Journal of Personality and Social Psychology, 61, 459-470.

Emmons, R. A. \& King, L. A. (1989). Personal striving differentiation and affective reactivity. Journal of Personality and Social Psychology, 56, 478-484.

Eysenck, H. J. (1967). The biological basis of personality. Springfield, Ill.: Thomas.

Eysenck, H. J. (1981). General features of the model. In Eysenck, H. J. (Ed.), A model for personality (pp. 1-37). New York: Springer.

Eysenck, H. J. \& Eysenck, M. W. (1985). Personality and individual differences: A natural science approach. New York: Plenum Press.

Eysenck, H. J. \& Eysenck, S. B. G. (1975). Manual of the Eysenck personality questionnaire (adult). London: Hodder \& Stoughton.

Fowles, D. C. (1980). The three arousal model: Implications of Gray's two-factor learning theory for heart rate, electrodermal activity, and psychopathy. Psychophysiology, 17, 87-104.

Fowles, D. C. (1987). Application of a behavioral theory of motivation to the concepts of anxiety and impulsivity. Journal of Research in Personality, 21, 417-435. 
Frijda, N. H. (1988). The laws of emotion. American Psychologist, 41, 349-358.

Fujita, F., Diener, E. \& Sandvik, E. (1991). Gender differences in negative affect and well-being: The case for emotional intensity. Journal of Personality and Social Psychology, 61, 427-434.

Gray, J. A. (1981). A critique of Eysenck's theory of personality. In Eynsenck, H. J. (Ed.), A model for personality (pp. 246-276). New York: Springer.

Gray, J. A. (1987). Perspectives on anxiety and impulsivity: A commentary. Journal of Research in Personality, 2l, 493-509.

Jancke, L. (1993). Different facial EMG-reactions of extraverts and introverts to pictures with positive, negative and neutral valence. Personality and Individual Differences, 14, 113-118.

Larsen, R. L. \& Diencr, E. (1985). A multitrait-multimethod examination of affect structure: Hedonic level and emotional intensity. Personality and Individual Differences, 6, 631-636.

Larsen, R. L. \& Diener, E. (1987). Affect intensity as an individual difference characteristic: A review. Journal of Research in Personality, $21,1-39$.

Larsen, R. J. \& Ketelaar, T. (1991). Personality and susceptibility to positive and negative emotional states. Journal of Personality and Social Psychology, 61, 132-140.

Russell, J. A. (1980). A circumplex model in affect. Journal of Personality and Social Psychology, 39, 1161-1178.

Russell, J. A. (1991). Culture and the categorization of emotions. Psychological Bulletin, 110, 426-450.

Strelau, J. (1987). Emotion as a key concept in temperament research. Journal of Research in Personality, 21, 510-528.

Wallace, J. F., Bachorowski, J. A. \& Newman, J. P. (1991). Failures of response modulation: Impulsive behavior in anxious and impulsive individuals. Journal of Research in Personality, 25, 23-44.

Watson, D. \& Tellegen, A. (1985). Toward a consensual structure of mood. Psychological Bulletin, 98, $219-235$.

\section{APPENDIX}

Emotional Intensity Scale

Imagine yourself in the following situations and then choose the answer that best describes how you usually feel.

1. Someone compliments me. I feel:

1. It has little effect on me.

Positive

2. Mildly pleased.

3. Pleased.

4. Very pleased.

5. Ecstatic- on top of the world.

2. I think about awful things that might happen. I feel:

1. It has little effect on me

2. A little worried.

Negative

3. Worried.

4. Very worried.

5. So extremely worried that I can almost think of nothing else.

3. I am happy. I feel:

1. It has little effect on me.

2. Mildly happy.

3. Happy

4. Extremely happy,

5. Euphoric - so happy I could burst.

4. I see a child suffer. I feel:

1. It has little effect on me.

2. A little upset.

3. Upset.

4. Very upset.

5. So extremely upset I feel sick to my stomach.

5. Someone I am very attracted to asks me out for coffee. I feel:

1. Ecstatic-on top of the world.

2. Very thrilled.

Positive

3. Thrilled.

4. Mildly thrilled.

5. It has little effect on me.

6. Something frustrates me. I feel:

1. It has little effect on me.

2. A little frustrated.

Positive

3. Frustrated.

4. Very frustrated.

5. So extremely tense and frustrated that my muscles knot up. 
7. I achieve a personal best in my favorite sport. I feel:

1. It has little effect on me.

Positive

2. Mildly pleased.

3. Happy.

4. Very happy.

5. Ecstatic- on top of the world.

8. I say or do something I should not have done. I feel:

1. It has little effect on me.

Negative

2. A twinge of guilt

3. Guilty.

4. Very guilty.

5. Extremely guilty.

9. I am at the park with a favorite child. I feel:

1. It has little effect on me.

Positive

2. Slightly playful

3. Playful

4. Very playful.

5. So playful I feel like running around the park.

10. Someone criticizes me. I feel:

1. It has little effect on me.

Negative

2. I am a bit taken aback

3. Upset.

4. Very upset.

5. So extremely upset I could cry.

11. I receive positive feedback from a favorite professor. I feel:

1. Thrilled-so happy I could burst.

Positive

2. Very happy.

Reverse Key

3. Happy.

4. Mildly pleased.

5. It has little effect on me

12. People do things to annoy me. I feel:

1. It has little effect on me

Negative

2. A little bothered.

3. Annoyed.

4. Very annoyed.

5. So extremely annoyed I feel like hitting them.

13. I hear a speech by a leader whose ideas I respect. I feel:

1. It has little effect on me.

Positive

2. Slightly impressed.

3. Impressed.

4. Very impressed.

5. Inspired-so impressed I have a new sense of purpose.

14. I have an embarrassing experience. I feel:

1. It has little effect on me.

Negative

A little ill at ease.

3. Embarrassed.

4. Very embarrassed.

5. So embarrassed I want to die.

15. Someone I know is rude to me. I feel:

1. So incredibly hurt I could cry.

2. Very hurt.

Negative

3. Hurt.

4. A little hurt.

5. It has little effect on me.

16. I am at a fun party. I feel:

1. It has little effect on me.

Positive

2. A little lighthearted.

3. Lively.

4. Very lively.

5. So lively that I almost feel like a new person. 
17. Something wonderful happens to me. I feel:

1. Extremely joyful-exuberant.

Positive

2. Extremely glad.

Reverse Key

3. Glad.

4. A little glad.

5. It has little effect on me.

18. I see a sad movie. I feel:

1. So extremely sad that I feel like weeping.

Negative

2. Very sad.

4. A little sad.

5. It has little effect on me.

19. I have accomplished something valuable. I feel:

1. It has little effect on me.

Positive

2. A little satisfied.

3. Satisfied.

4. Very satisfied.

5. So satisfied it's as if my entire life was worthwhile.

20. Something angers me. I feel:

I. It has little effect on me.

2. A little angry.

3. Angry.

4. Very angry.

5. So angry I could explode.

Negative

21. A person with whom I am involved prepares me a candlelight dinner. I feel:

1. It has little effect on me.

Positive

2. Slightly romantic.

3. Romantic.

4. Very romantic.

5. So passionate nothing else matters.

22. I have hurt someone's feelings. I feel:

1. It has little effect on me.

Negative

2. A little sorry.

3. Sorry.

4. Very sorry.

5. So extremely sorry I will do anything to make it up to them.

23. I am late for work or school and I find myself in a traffic jam. I feel:

1. In a rage.

Negative

2. Very angry.

Reverse Key

3. Angry.

4. Slightly angry.

5. It has little effect on me.

24. I am involved in a situation in which I must do well, such as an important exam or job interview. I feel:

1. It has little effect on me.

Negative

2. Slightly anxious.

3. Anxious.

4. Very anxious.

5. So extremely anxious I can think of nothing else.

25. My boss gives me an unexpected pat on the back and says, 'nice work'. I feel:

1. Exuberant-my day is perfect.

2. Very gratified.

3. Gratified.

4. Slightly gratified.

5. It has little effect on me. 
26. I am involved in a romantic relationship. I feel:

1. So consumed with passion I can think of nothing else.

Positive

2. Very passionate.

Reverse Key

3. Passionate

4. Mildly passionate.

5. It has little effect on me.

27. I attend the funeral of a casual acquaintaince. I feel:

1. It has little effect on me.

2. Mildly sad.

Negative

3. Sad.

4. Very sad.

5. So extremely sad that I cannot control my tears.

28. I am in an argument. I feel:

1. It has little effect on me.

2. Mildly angry.

Negative

3. Angry.

4. Very angry.

5. So incredibly angry I find it difficult to remain composed.

29. Payments on my bills are overdue. I feel:

1. In such a panic 1 can think of nothing else.

Negative

2. Very worried.

Reverse Ke

3. Worried.

4. Mildly worried.

5. It has little effect on me.

30. Someone surprises me with a gift. I feel:

1. It has little effect on me.

Positive

2. A little grateful.

3. Grateful.

4. Very grateful.

5. So grateful I want to run out and buy them a gift in return. 